\title{
A NEW METHOD OF TEACHING FIGURATIVE EXPRESSIONS TOIRANIAN LANGUAGE LEARNERS
}

\author{
Leila Erfaniyan Qonsuli and Mostafa Bahraman
}

Assistant Professor, Kashmar Higher Education Institute, Iran

\begin{abstract}
In teaching languages, if we only consider direct relationship between form and meaning in language and leave psycholinguistic aside, this approach is not a successful practice and language learners won't be able to make a successful relation in the real contexts. The present study intends to answer this question: is the teaching method in which salient meaning is taught more successful than the method in which literal or figurative meaning is taught or not? To answer the research question, 30 students were selected. Every ten people are formed as a group and three such groups were formed. Twenty figurative expressions were taught to every group. Group one was taught the figurative meaning of every expression. Group two was taught the literal meaning and group three was taught the salient meaning. Then three groups were tested. After analyzing data, we concluded that there was a significant difference in mean grades between classes and the class trained under graded salience hypothesis was more successful. This shows that traditional teaching methods must be revised.
\end{abstract}

\section{KEYWORDS}

Teaching, Graded Salient Hypothesis, Figurative expressions, Language

\section{INTRODUCTION}

A strong foundation in teaching languages is psycholinguistics and cognitive linguistics so that language teaching and psycholinguistics are not detachable. The significance of psycholinguistic and cognitive research is best known when the result of researches show that Most of the time we speak, we speak not straight and usually we say something but we mean something else. For example we say "it's cold today" but we mean" please close the door". This has gone so far that most psycholinguists and cognitive linguists believe that even our thinking is metaphorical. Therefore, in teaching languages, if we only consider direct relationship between form and meaning in language and leave psycholinguistic aside, this approach is not a successful practice and language learners won't be able to make a successful relation in the real contexts. According to Graded Salience Hypothesis (Giora, 1997), more salient meanings-coded meanings foremost on our mind due to conventionality, frequency, familiarity, or prototypicality-are accessed faster than and reach sufficient levels of activation before less salient ones. even rich and supportive contexts which are biased in favor of less salient meanings do not inhibit activation of salient meanings. This hypothesis predicts that in teaching languages, it's more successful to teach the 
salient meaning of figurative expressions, not figurative or literal meaning. The present study intends to answer this question: is the teaching method in which salient meaning is taught more successful than the method in which literal or figurative meaning is taught or not?

\section{LITERATURE REVIEW}

Kecskes(1999)claims that pragmatic skills in an L2 do not necessarily reflect conceptual fluency in the target language properly because individual variables rather than conceptual fluency play a decisive role in the selection and use of these pragmatic units. In order to investigate the validity of this hypothesis a survey was conducted with 88Non-Native Speakers (NNSs) and 33 Native Speakers of English (NSs) who were given three types of tests: two discourse-completion tests, a problem-solving test and a dialog interpretation test. Data were analyzed for two variables: cultural specificity of SBUs and individual learner strategies. The findings of the survey demonstrated the existence of three developmental stages which are characterized respectively by strong L1-culturetransfer, false generalization, individual choice. Students in the third stage tend to choose SBUs on affective grounds and reject those pragmatic units which they find too culture specific.

Kecskes(2006) discusses three claims of the Graded Salience Hypothesis presented in Rachel Giora's book 'On our mind'. It is argued that these claims may give second language researchers the chance to revise the way they think about word meaning, the literal meaning-figurative meaning dichotomy and the role of context in language processing. Giora's arguments are related to recent second language research and their relevance is explained through examples. There are also several suggestions made for further research.

Kecskes(2000) considered a particular type of formulaic expressions called situation-bound utterances (SBUs). Since the meaning of these pragmatic units is shaped by the interplay of linguistic and extra linguistic factors, they can be best accounted for in a theoretical framework which represents a knowledge-for-use conception. A cognitive-pragmatic approach to SBUs reveals that in many cases cognitive mechanisms such as metaphor and conventional knowledge are responsible for the unique situational meaning of SBUs. In this respect, SBUs are similar to other formulaic expressions such as idioms and conventional implicatures whose meaning structure can also be better accounted for if the underlying cognitive mechanisms are examined. It will be claimed that the relationship of SBUs to socio-cultural concepts resembles that of words and concepts as described in Cruse (1992). SBUs will be classified according to their formula-specific pragmatic properties which are either encoded in the expression or charged by the situation. The investigation of the characteristic features of SBUs and the development of their situational meaning necessitates the review of two important theoretical issues: the creative aspect of language use and the role of formulaic expressions in the development of syntax. It will be argued that the formulaic-creative dichotomy makes sense only at sentence level, whereas it loses its significance at discourse level. Not all types of formulaic expressions contribute to syntactic development in an L2, because some of them (including SBUs) are almost never split into constituents by L2 learners. Errors in the use of SBUs can mainly be due to the lack of native-like conceptual fluency and metaphorical competence of adult L2 learners, who rely on their LI conceptual system when producing and comprehending SBUs in the target language. 
Abel(2003) In two empirical studies, investigated judgments that native speakers of German make about the decomposability of English idioms. A decomposable idiom is an idiom whose individual components contribute to its figurative meaning, whereas the constituents of a non decomposable idiom do not make such a contribution. The findings were analysed and compared to native judgments. The Model of Dual Idiom Representation is introduced in order to explain the differences between the two groups. At the lexical level, the model postulates the parallel existence of idiom entries and constituent entries. The degree of decomposability and the frequency with which the idiom is encountered determine its lexical representation. If there is no idiom entry for a particular idiom, conceptual representations are accessed during comprehension. Because non native speakers encounter idioms less often than native speakers, the first language (L1) and second language (L2) lexicon vary with regard to the number of idiom entries.

In a research by Bortfeld(2003), Speakers of three different languages (English, Latvian, and Mandarin) rated sets of idioms from their language for the analyzability of the relationship between each phrase's literal and figurative meaning. For each language, subsets of idioms were selected based on these ratings. Latvian and Mandarin idioms were literally translated into English. Across three experiments, people classified idioms from the three languages according to their figurative meanings. Response times and error rates indicate that participants were able to interpret unfamiliar (e.g., other languages') idioms depending largely on the degree to which they were analyzable, and that different forms of processing were used both within and between languages depending on this analyzability. Results support arguments for a continuum of analyzability (Bortfeld \& McGlone, 2001), along which figurative speech ranges from reflecting general conceptual structures to specific cultural and historical references.

Cies'licka(2013) aimed to explore the role of compositionality in the course of processing idioms by second language users. The study employed a cross-modal priming technique in which English decomposable and non decomposable idioms were embedded in sentences (e.g. 'George wanted to bury the hatchet soon after Susan left') and presented auditorily via headphones to Polish fluent speakers of English. While participants were listening to the sentence, a target word related figuratively (e.g. FORGIVE) or literally (e.g. AXE) to the idiom was presented on the computer screen for a lexical decision either at the end of the idiom or before the last word of the idiom. Contrary to the predictions of the Idiom Decomposition Hypothesis (Gibbs and Nayak 1989; Gibbs et al. 1989), figurative meanings of decomposable idioms were not available faster than those of non decomposable idioms. In addition, strong activation was found for literal meanings of idiom constituents, in line with previous L2 processing research (Kecskes 2000; Liontas 2002; Abel 2003).

\section{THEORETICAL FRAMEWORK}

In this part, the graded salience hypothesis (Giora, 1997) will be discussed.

\subsection{Literal meaning-figurative meaning}

- Literal meaning has been defined as linguistic meaning, i.e., as nonfigurative, coded, fully compositional, context-invariant, explicit, and truth conditional (Katz, 1977, in Ariel, 2002). 
- Figurative meaning is seen as its counterpart, i.e., as extra linguistic, indirect, inferred, noncompositional, context-dependent, and cancelable (Ariel, 2002).

\subsection{Graded Salience Hypothesis}

According to the graded salience hypothesis (Giora, 1997), for information to be salient- to be foremost on one's mind-it needs to undergo consolidation, that is, to be stored or coded in the mental lexicon.

Stored information is superior to unstored information such as novel information or information inferable from context: while salient information is highly accessible, nonsalient information requires strongly supportive contextual information to become as accessible as salient information. Salience is not an either-or notion, however. Rather, it admits degrees. The more frequent, familiar, conventional, or prototypical/stereotypical the information in the mind of the individual or in a certain linguistic community, the more salient it is in that mind or among the community members (Giora, 2003:15).

\subsection{Graded Salience Hypothesis Predictions}

The Graded Salience Hypothesis has predictions regarding the first phase and the second phase of comprehension. It predicts that comprehension involves an initial phase in which contextually appropriate and salient meanings are activated-the latter automatically and independently of contextual information, the former as a result of a predictive context - and an immediate subsequent phase of integration in which the activated meanings are either retained for further processes or suppressed as contextually disruptive. This holds for any stage of the comprehension processes (Giora, 2003: 37).

\subsection{Familiarity}

The more familiar the meaning, the quicker it is to retrieve (Blasko\&Connine, 1993; Gernsbacher, 1984; Hintzman\& Curran, 1994). Given enough exposure and individual experience, any information can become foremost on our mind to the extent that it resists contextual information (see Zajonc, 2000); so the salience depends on the experiential familiarity an individual has with the stimulus in question.

\subsection{Figurative Language}

In the psychological literature, eight distinct types of nonliteral language have emerged (Kreuz\& Roberts, 1993). In figurative expressions, figurative meaning is intended, not literal meaning.

\section{RESEARCH METHOD}

To answer the research question, 30 Iranian students of English translation field of study, aged 18-22, and female gender were selected. Every ten people are formed as a group and three such groups were formed. In a week, twenty figurative expressions were taught to every group. The materials used were 20 indirect requests or idioms taken from naturally occurring conversations; such as the following: « it is cold! »(It means: close the door!). A pretest was performed. Tennative English speakers participated. In this pretest, participants rated the expressions on a 1- 
7 familiarity scale, in which $7=$ highly familiar and $1=$ entirely unfamiliar. Then, expressions were divided into familiarity groups (familiar, less-familiar, unfamiliar). Therefore the salient meaning was obtained. For the main test, Group one was taught the figurative meaning of every expression. Group two was taught the literal meaning and group three was taught the salient meaning. Then three groups were tested and the meaning of expressions was asked.

\section{DATA ANALYSIS}

Chi-Square Testwas used for the pretest. Then, expressions were divided into familiarity groups (familiar, less-familiar, unfamiliar). Foranalyzing the results of main test, t-Test was used and sig $=0.022<0.05$. This indicated thatthere was a significant difference in mean grades between classes.

Table 1.Samples Statistics

\begin{tabular}{|c|c|c|c|c|}
\hline & Mean & N & Std. Deviation & Std. Error Mean \\
\hline v3 & 12.3000 & 20 & 3.15561 & .70562 \\
v4 & 14.9000 & 20 & 2.66853 & .59670 \\
\hline
\end{tabular}

Table 2.Samples Correlations

\begin{tabular}{|c|c|c|c|}
\hline & $\mathbf{N}$ & Correlation & Sig. \\
\hline $\mathrm{v} 3 \& \mathrm{v} 4$ & 20 & -.271 & .247 \\
\hline
\end{tabular}

Table 3.Samples Test

\begin{tabular}{|c|c|c|c|c|c|c|c|c|}
\hline & \multicolumn{5}{|c|}{ Paired Differences } & \multirow[b]{3}{*}{$\mathbf{t}$} & \multirow[b]{3}{*}{ df } & \multirow{3}{*}{$\begin{array}{l}\text { Sig. (2- } \\
\text { tailed) }\end{array}$} \\
\hline & \multirow[b]{2}{*}{ Mean } & \multirow[b]{2}{*}{$\begin{array}{c}\text { Std. } \\
\text { Deviation }\end{array}$} & \multirow{2}{*}{$\begin{array}{l}\text { Std. } \\
\text { Error } \\
\text { Mean }\end{array}$} & \multicolumn{2}{|c|}{$\begin{array}{l}\text { 95\% Confidence } \\
\text { Interval of the } \\
\text { Difference }\end{array}$} & & & \\
\hline & & & & Lower & Upper & & & \\
\hline $\mathrm{v} 3-\mathrm{v} 4$ & -2.60000 & 4.65267 & 1.04037 & -4.77752 & -.42248 & -2.499 & 19 & .022 \\
\hline
\end{tabular}

\section{DISCUSSION AND CONCLUSION}

After analyzing data, we concluded that there was a significant difference in mean grades between classes and the class trained under graded salience hypothesis was more successful. This shows that traditional teaching methods must be revised.

Graded salience hypothesis provides new insights supported by empirical evidence that prompt the reader to revise his or her views about L2 language processing, vocabulary acquisition, pragmatics and reading. It has much to offer to applied linguists. This Hypothesis has already begun and has produced some interesting results (Abel, 2003;Bortfeld, 2002; 2003; Cies'licka, forthcoming). The investigation of salience in second language acquisition should allow us to understand how emerging new conceptual knowledge blends with existing L1-based conceptual knowledge, resulting in the development of a new complex language system and modifications in 
the operation of the L1. The GSH may help us develop an intake theory that focuses not only on input and output as the inter language approach does, but that attempts to explain what happens in the mind of language learners as they process new input(Kecskes,2006).

\section{REFERENCES}

[1] Abel, Beate, (2003), English idioms in the first language and second language lexicon: a dual representation approach, Second Language Research 19,4; pp. 329-358.

[2] Ariel, M. (2002).the Demise of a Unique Literal Meaning. Journal of Pragmatics, 34, 361-402.

[3] Blasko, G. D. \&Connine, C. (1993).Effects of Familiarity and Aptness on Metaphor Processing. Journal of Experimental Psychology: Learning, Memory, and Cognition,19, 295-308.

[4] Bortfeld, H., \&McGlone, M. (2001). The continuum of metaphor processing.Metaphor and Symbol, $16,75-86$.

[5] Bortfeld, H.,(2002), What native and non-native speakers' images for idioms tell us about figurative language. In Heredia, R. and Altarriba, J., editors, Bilingual Sentence Processing.North Holland/Elsevier, 275-95.

[6] Bortfeld, Heather, (2003), Comprehending Idioms CrossLinguistically, Experimental Psychology; Vol. 50(3): 217-230.

[7] Cies'licka, Anna B. , (2013), Second Language Learners' Processing of Idiomatic Expressions: Does Compositionality Matter? Second Language Learning and Teaching, Series Editor MirosławPawlak, KrystynaDroz'dział-Szelest. , Studies in Honor of WaldemarMarton,springer, 115-136.

[8] Cruse, D.A., (1992), Antonymy revisited: Some thoughts on the relationship between words and concepts. In: A. Lehrer and E. Kittay, eds., Frames, fields and contrasts, Hillsdale, 289-309: Erlbaum.

[9] Gernsbacher, M. A. (1984). Resolving Twenty years of Inconsistent Interactions between Lexical Familiarity and Orthography, Concreteness, and Polysemy. Journal of Experimental Psychology: General, 113, 256-281.

[10] Gibbs, R. W., N. P. Nayak and C. Cutting. (1989), How to kick the bucket and not decompose: Analyzability and idiom processing. Journal of Memory and Language28: 576-593.

[11] Gibbs, R. W. and N. P. Nayak.(1989), Psycholinguistic studies on the syntactic behavior of idioms. Cognitive Psychology21: 100-138.

[12] Giora, R. (1997). Understanding Figurative and Literal Language: the Graded Salience Hypothesis. Cognitive Linguistics, 8(3), 183-206.

[13] Giora, R. (2003). On Our Mind: Salience, Context, and Figurative Language. Oxford University Press.

[14] Hintzman, D. L. \& Curran, T. (1994). Retrieval Dynamics of Recognition and Frequency Judgements: Evidence for Separate Processes of Familiarity and Recall. Journal of Memory and Language, 33, 1-18.

[15] Katz, A. N. (1977). Propositional Structure and Illocutionary Force.NewYork: Thomas Y.Crowell. 
[16] Kecskes, Istvan, (1999), Conceptual fluency and the use of situation-bound utterances in L2, Links \& Letters 7, 145-161.

[17] Kecskes, Istvan, (2000),A cognitive-pragmatic approach to situation-bound utterances, Journal of Pragmatics 32 , 605-625.

[18] Kecskes, Istvan, (2006), On my mind: thoughts about salience, context and figurative language from a second language perspective, Second Language Research 22,2; pp. 1-19.

[19] Kreuz, R, J. \& Roberts, R. M. (1993).the Empirical Study of Figurative Language in Literature. Poetics, 22, 151-169.

[20] Liontas, J. 2002. Context and idiom understanding in second languages.In EUROSLA Yearbook, eds. S. H. Foster-Cohen, T. Ruthenberg and M. L. Poschen, 155-185. Amsterdam: John Benjamins Publishing Company.

[21] Zajonc, R. B. (2000). Closing the Debate Over the Independence of Affect. In J. P. Forgas(Ed.), Feeling and thinking: the Role of Affect in Social Cognition(31-58). Cambridge: Cambridge University Press.

\section{AUTHOR}

Leila ErfaniyanQonsuli

\section{EDUCATION}

- B.A.: English Language and Literature(University of Sistan and Baluchestan, Zahedan, Iran)

- M.A.: General Linguistics(Ferdowsi University of Mashhad, Mashhad, Iran)

- Ph.D: General Linguistics(Ferdowsi University of Mashhad, Mashhad, Iran)

\section{HONORS AND DISTINCTIONS}

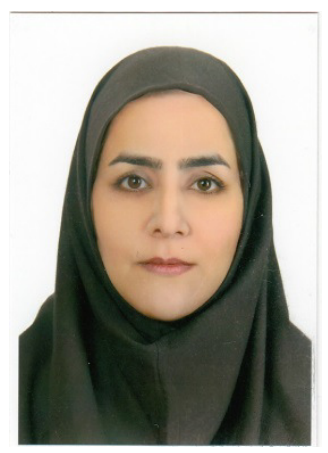

- Earn the rank of "A" (the first person in Iranian`s Ph.D. entrance exam)

- Earn the rank of "A" among Ph.D. students in Ferdowsi university of Mashhad (Top graduate student with the Top GPA. of A+).

- Earn the rank of "A" (the first person in Iranian`s MA. entrance exam)

- Earn the rank of "A" among MA. Students in Ferdowsi university of Mashhad (Top graduate student with the Top GPA. of A+).

- A member of Iranian elite center.

- Earn the third rank of the best Ph.D. thesis in Iran.

- Earn the excellent rank for MA. Thesis (GPA: A+).

- Earn the excellent rank for Ph.D. Thesis (GPA: A+).

- Earn the "Best professor" title from scientific and applied university.

- Earn the "Best married student" title from Ferdowsi university of Mashhad.

- Earn the "Best student" title from Ferdowsi university of Mashhad multiple times.

- A member of "applied psycholinguistics" journal reviewers.

- A member of "Khorasan`s dialects and linguistics" of Ferdowsi university journal reviewers.

- A member of "Literary and rhetorical studies" journal of PayameNour university.

- Supervisor and advisor and professor in MA. theses.

- Author of multiple published paper s in scientific journals 